\title{
Displacement Fields of Sedimentary Layers Controlled by Fault Parameters: The Discrete Element Method of Controlling Basement Motions by Dislocation Solutions
}

\author{
Shigekazu Kusumoto ${ }^{1}$, Yasuto Itoh $^{2}$, Keiji Takemura ${ }^{3}$, Tomotaka Iwata ${ }^{4}$ \\ ${ }^{1}$ Graduate School of Science and Engineering for Research, University of Toyama, Gofuku, Toyama, Japan \\ ${ }^{2}$ Graduate School of Science, Osaka Prefecture University, 1-1 Gakuen-cho, Nakaku, Sakai, Osaka Japan \\ ${ }^{3}$ Institute for Geothermal Sciences, Graduate School of Science, Kyoto University, Kitashirakawa oiwake-cho, Sakyo-ku, Kyoto, Japan \\ ${ }^{4}$ Disaster Prevension Research Institute, Kyoto University, Gokasho, Uji, Kyoto, Japan
}

\section{Email address:}

kusu@sci.u-toyama.ac.jp (S. Kusumoto), itoh@p.s.osakafu-u.ac.jp (Y. Itoh), takemura@bep.vgs.kyoto-u.ac.jp (K. Takemura), iwata@egmdpri01.dpri.kyoto-u.ac.jp (T. Iwata)

\section{To cite this article:}

Shigekazu Kusumoto, Yasuto Itoh, Keiji Takemura, Tomotaka Iwata. Displacement Fields of Sedimentary Layers Controlled by Fault Parameters: The Discrete Element Method of Controlling Basement Motions by Dislocation Solutions. Earth Sciences.

Vol. 4, No. 3, 2015, pp. 89-94. doi: 10.11648/j.earth.20150403.11

\begin{abstract}
In the two-dimensional discrete element modeling of displacement of sedimentary layers caused by faulting within the basement, we attempted to move a rigid basement as if it were an elastic basement by controlling its motion through application of dislocation solutions. An advantage of our modeling procedure is that we can discuss displacement fields of sedimentary layers in connection with fault parameters. We simulated displacement fields of the sedimentary layers by means of our modeling procedure and found that our simulated fields are different from the fields obtained in rigid basement models and are dependent on the selected fault parameters.
\end{abstract}

Keywords: Displacement Fields of Sedimentary Layers, Two-Dimensional Discrete Element Modeling, Dislocation Solutions, Fault Parameters, Rigid Basement, Elastic Basement

\section{Introduction}

The discrete element method [1,2] is one of the most powerful numerical tools for simulating nonlinear structural phenomena, such as large deformations and fracture initiation and propagation. This modeling procedure has been applied not only to engineering fields $[3,4]$ but also to a number of geological and geophysical problems $[5,6,7,8,9,10,11,12$, $13,14,15]$.

References [16, 17, 18] investigated how an inhomogeneity in a sedimentary layer or the dip angle of a fault, or both, affect the displacement field of the sedimentary layer. Reference [19] showed that the mechanical conditions (e.g., homogeneity or inhomogeneity) of layers determine the forms of the resulting deformation in sedimentary layers (e.g., transition from trishear to kink-band fault propagation fold). These studies have given us extensive knowledge about the displacement processes of sedimentary layers caused by fault motions. However, in a series of studies, displacements of sedimentary layers have been simulated by the basement motion, simplified as shown in Fig. 1(a). Walls are treated as rigid bodies, the same as elements in discrete element modeling. The actual basement does not behave as rigid material, and these models cannot provide information on the magnitude of fault motion, especially in a two-dimensional analysis.

In this study, we employed Okada's dislocation solutions [20] for calculation of the basement displacement caused by faulting. Okada's dislocation solutions provide expressions for deriving surface displacement fields, which are caused by the movement of dislocation planes embedded in an elastic isotropic half-space without the effect of the gravitational field. Hence, in the strict sense, the solutions cannot be used to derive exact values for deformation fields for the basements covered by sedimentary layers. In fact, these would only give first-order approximations of the basement deformation fields, especially in case of thick sedimentary layers. However, the advantage of employing the solutions for calculating basement displacements is that the displacement fields of sedimentary layers can be considered in connection with fault parameters. This feature is useful in interpreting and discussing the 
observed data in terms of both geology and geophysics, although nature is not so simple and behaves in complicated manner. Here, we utilized a commercial software package,
Particle Flow Code in two dimensions ( $\mathrm{PFC}^{2 \mathrm{D}}$; Itasca, Minneapolis, USA [21]), as discrete element analysis software.

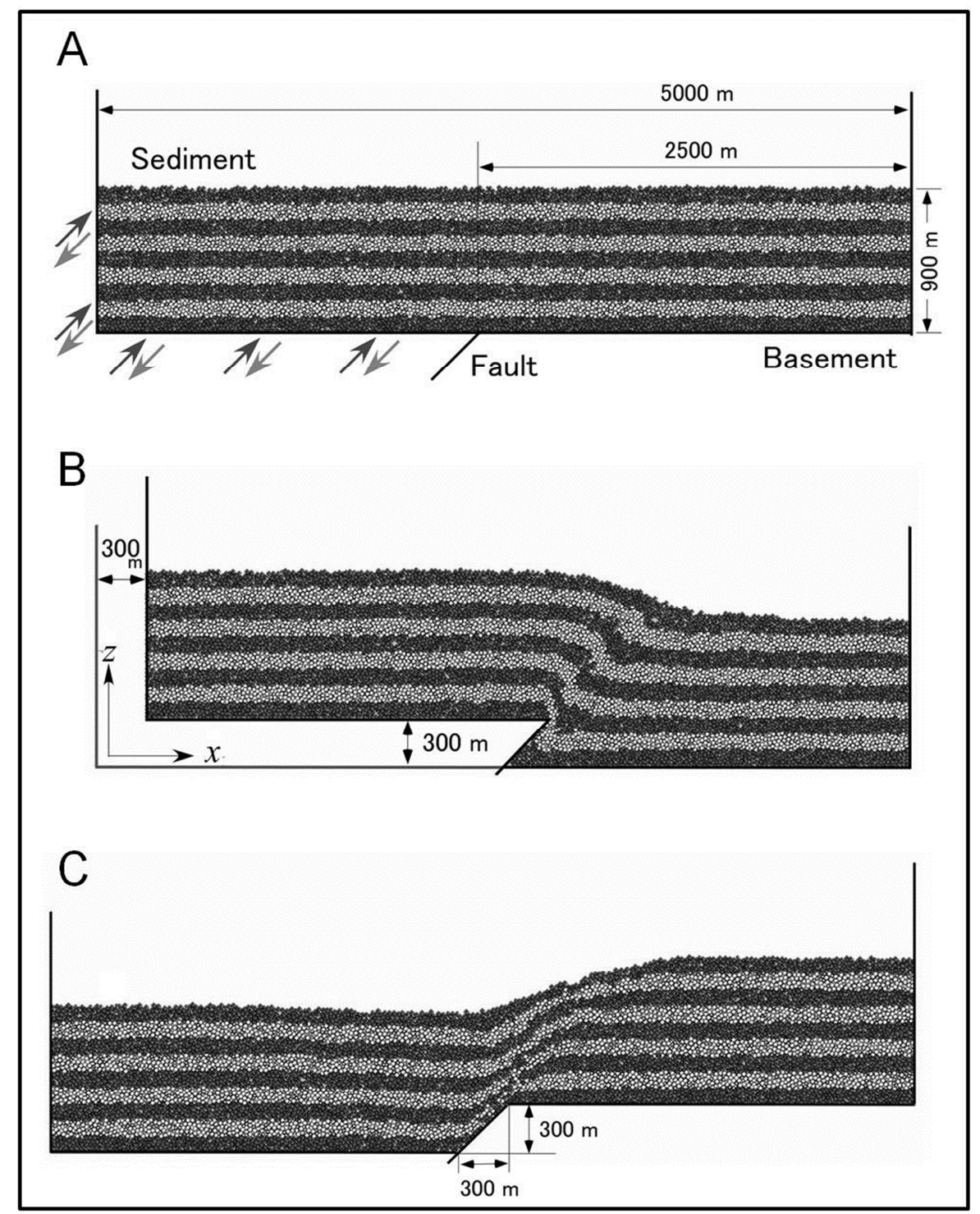

Figure 1. Discrete element model in which the basement is treated as a rigid body. A: Discrete element model of the sedimentary layers. The model has a thickness and width of $900 \mathrm{~m}$ and $5000 \mathrm{~m}$, respectively. The sedimentary layers are homogeneous and isotropic and the layers are dark gray and light gray, with $100 \mathrm{~m}$ intervals, to find deformation fields caused by fault motions. The sedimentary layers are assumed to be unconsolidated sediment, with low Young's modulus and strength. The radiuses of the elements were given randomly in the range 15.88-23.83 $\mathrm{m}$. The spring constants are $5 \times 10^{8} \mathrm{~N} / \mathrm{m}$ in both normal and shear directions, the friction coefficient is 0.6 , and the contact bond (controlling the strength of materials) is $10^{6} \mathrm{~N}$. The medium consisting of assemblies of disks with these parameters is equivalent to a sediment layer with Young's modulus, Poisson's ratio, and compressive strength of 207 MPa, 0.24, and 13 MPa, respectively. Dark gray and light gray arrows show the moving directions of the wall that would be moved in the modeling of reverse fault motion and normal fault motion, respectively. B: Deformation field of the sedimentary layers caused by reverse fault motion. The reverse fault has a dip angle of $45^{\circ}$ and has accumulated $300 \mathrm{~m}$ of movement in the vertical direction. The shortening caused by this reverse faulting is $300 \mathrm{~m}$ because of the dip angle of $45^{\circ}$. C: Deformation field of sedimentary layer caused by normal fault motion. The normal fault has a dip angle of $45^{\circ}$ and has accumulated $300 \mathrm{~m}$ of movement in the vertical direction. The expansion caused by this normal faulting is $300 \mathrm{~m}$ because of the dip angle of $45^{\circ}$.

\section{Rigid Basement and Elastic Basement}

Fig. 2 shows the shapes of basement deformed by reverse faulting and normal faulting. The faults are assumed to have a dip angle of $45^{\circ}$ and an accumulative vertical displacement of $300 \mathrm{~m}$.

The hollow circulars $\bigcirc$ and the solid circulars $\bullet$ in Fig. 2 represent basement shapes calculated by the dislocation solutions. The hollow circulars indicate the basement shape caused by motion of a fault having a bottom depth of $15 \mathrm{~km}$, and the solid circulars indicate the basement shape caused by motion of a fault having a bottom depth of $2.5 \mathrm{~km}$, although the bottom depth of $2.5 \mathrm{~km}$ might not be realistic. In addition to the fault depths, we assumed in the dislocation modeling that the fault reaches the surface and that its length in the strike direction is $30 \mathrm{~km}$ with assuming a Poisson's ratio of 0.25 . 
From Fig. 2, we found that the elastic basement has a tilt in both the footwall and the hanging wall and that the vertical deformation reduced rapidly with increasing horizontal distance from the fault when the depth of the fault bottom was shallow.

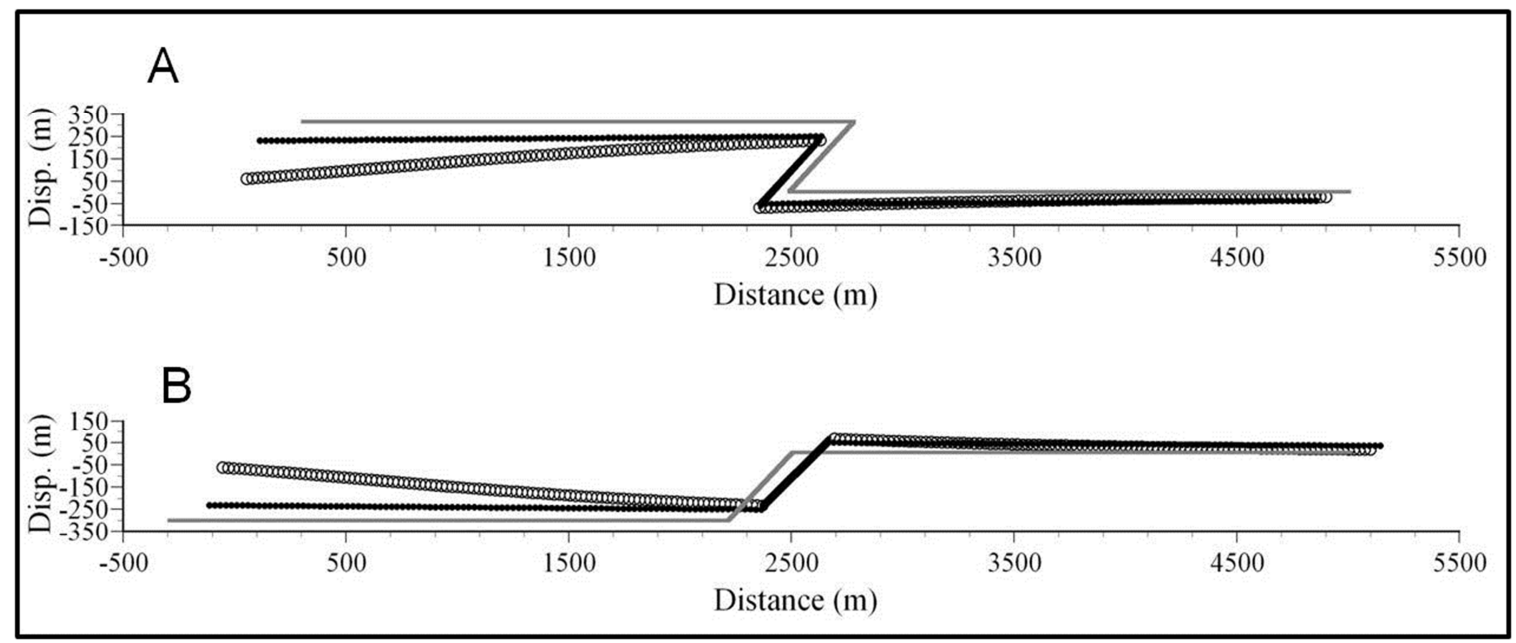

Figure 2. Displacement forms of basement caused by fault motion. Gray lines show the basement form in the rigid model. Hollow circulars $\circ$ and solid circulars indicate the elastic basement shapes caused by motion of the reverse fault with a bottom depth of $15 \mathrm{~km}$ and of $2.5 \mathrm{~km}$, respectively. Displacements of the elastic basement are controlled by Okada's dislocation solutions [20]. A: Basement shapes deformed by reverse faulting. B: Basement shapes deformed by normal faulting.

The gray lines in Fig. 2 illustrate the shape of the rigid basement, which moved according to the model shown in Fig. 1(a). In this model, the basement is treated as a rigid body. Thus, its shape will not be deformed and just will be moved by translational and/or rotational motions.

Considering the above points, it seems that, even if the accumulative vertical displacements are the same, the selected basic basement model affects the shape of the basement, and the shape of an elastic basement is also controlled by fault parameters. The differences in basement shapes are expected to affect the deformation field of sedimentary layers overlying the basement.

\section{Modeling Procedure}

To express elastic behaviors of basement by use of rigid elements, we modeled the basement as an assembly of $n-1$ rigid walls divided by $n$ nodes (Fig. 3(a)), and we controlled the wall movements by use of the dislocation solutions. Concretely, at the $i$-th point, we added displacements $\left(\delta x_{i}, \delta z_{i}\right)$, given by the dislocation solutions, into the original coordinate values $\left(x_{i}, z_{i}\right)$ and created a new point, with new coordinate values $\left(x_{i}^{\prime}=x_{i}+\delta x_{i}, z_{i}^{\prime}=z_{i}+\delta z_{i}\right)$. We made a new wall with new points and deleted the existing wall with the old points (Fig. 3(b)). By repeating this procedure, we can move the rigid basement as if it were an elastic body.

The wall must be moved step by step to obtain stable solutions, because the motions of walls exert a large force on elements and disturb the convergence of solutions. In each step, displacements by small dislocations were assigned at each point. Through this calculation cycle, accumulative large deformation occurs in the basement and fault plane.

\section{Numerical Examples and Discussion}

To compare our modeling results with the previous modeling results (Figs. 1(b) and 1(c)), we used the sedimentary layer model shown in Fig. 1(a), that is, a sedimentary layer model with a size of $900 \mathrm{~m} \times 5000 \mathrm{~m}$, Young's modulus of $207 \mathrm{MPa}$, Poisson's ratio of 0.24 , and compressive strength of $13 \mathrm{MPa}$. In calculations of an elastic basement, we employed the same elastic constants and fault parameters as the parameters that gave the basement shape shown in Fig. 2. To give the accumulative fault displacement of $300 \mathrm{~m}$, we gave a fault slip of approximately $424 \mathrm{~m}$ on the fault plane because the dip angle was $45^{\circ}$. Calculations were divided into 60 steps, and a slip of $5 \sqrt{2} \mathrm{~m}$ per step was assigned to the fault plane. The basement was divided into 200 small rigid walls.

Results are depicted in Fig. 4. Figs. 4(a) and 4(b) show the deformation fields of sedimentary layers caused by the motions of a reverse fault, and their bottom depths are $15 \mathrm{~km}$ and $2.5 \mathrm{~km}$, respectively. Figs. 4(c) and 4(d) show the deformation fields of sedimentary layers caused by the motions of a normal fault, and their bottom depths are $15 \mathrm{~km}$ and $2.5 \mathrm{~km}$, respectively. All sedimentary layers tilted along with the deformation of the basement, and we found that the deformed basement shape controlled deformation of the sedimentary layers.

In the reverse fault model, the sedimentary layers have been deformed upward convexly in the case of the fault bottom depth of $15 \mathrm{~km}$ (Fig. 4(a)). In contrast, the sedimentary layers have been deformed downward convexly (Fig. 4(b)), in the case of the fault bottom depth of $2.5 \mathrm{~km}$. In addition, we found a small hollow at the top of the sedimentary layers on the hanging wall side (arrows in Figs. 4(a) and 4(b)), and the 
hollow seemed to appear on the hanging wall side boundary of the trishear. These deformation trends and the small hollow did not appear in the rigid basement models (Figs. 1(b) and 1(c)) and in the normal fault models (Figs. 4(c) and 4(d)).

In the normal fault model, we found an upheaval zone at the surface of the sedimentary layers on the footwall side (arrows in Figs. 4(c) and 4(d)). Since the normal fault motion formed upheaval and tilt in the elastic basement, the upheaval zones seem to have been formed by the basement shape. In addition, the gradient of the deformed sedimentary layer around the tip becomes gentle if the bottom depth of the fault is shallow. The deformation patterns did not appear in the rigid models (Figs. 1(b) and 1(c)) and in the reverse fault models (Figs. 4(a) and 4(b)).

These results show that the deformation field of the sedimentary layers was affected by the other fault parameters, even if the dip angle was the same. Consequently, there is a potential that our modeling procedure can specify the fault parameter that had played the most important role in forming flexure and/or fault-related fold. Knowledge of the deformation processes of sedimentary layers gained from studies of the rigid basement model [16, 17, 18, 19] is very useful and important for understanding the behavior of sedimentary layers, and this knowledge should be discussed in connection with the fault parameters.

The shapes of the deformed basement caused by fault motion can be calculated in arbitrary locations or profiles in cases where the dislocation solutions have been employed as shown in present study. Hence, if we apply this modeling procedure to interpretations of seismic reflections from seismic surveys, even if the seismic profiles are set obliquely onto faults, the basement forms can be modeled and the reflections can be interpreted without special procedures. In addition, because Okada's dislocation solutions are based on linear elasticity, the effects of more than one fault motion can be introduced into one model by the superposition principle of solutions, and it can be performed without extending the analytic area.

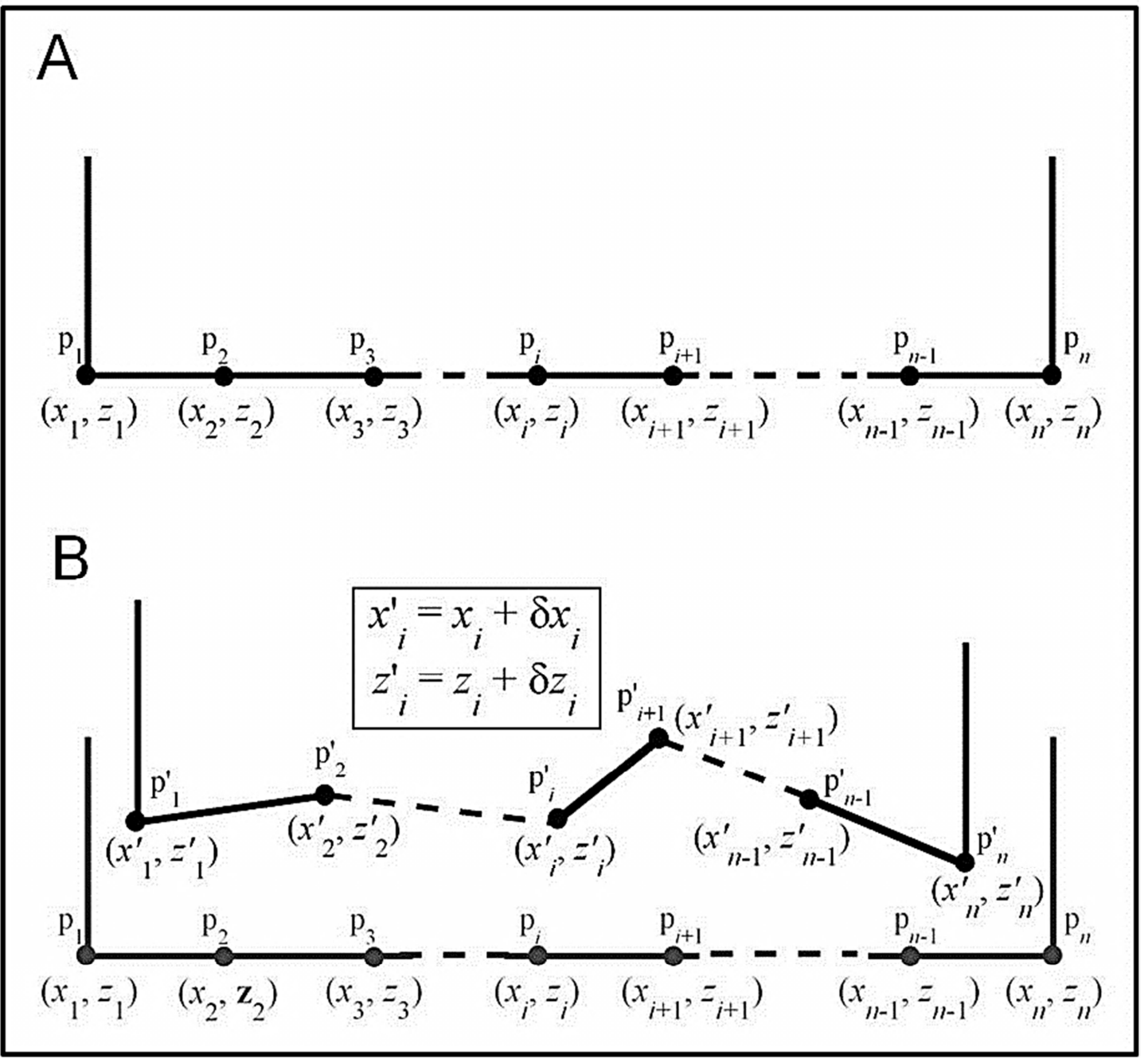

Figure 3. Schematic illustration of the procedure for introducing the dislocation solutions into the rigid basement and making the basement behave elastically. A: The basement is modeled as an assembly of $n-1$ rigid walls divided by n nodes. B: Displacements $\left(\delta x_{i}, \delta z_{i}\right)$ given by the dislocation solutions are added into the original coordinate values $\left(x_{i}, z_{i}\right)$ and new points are created as new coordinate values $\left(x_{i}^{\prime}=x_{i}+\delta x_{i}, z_{i}^{\prime}=z_{i}+\delta z_{i}\right)$. A new wall is created with new points and the existing wall with the old points is deleted. 


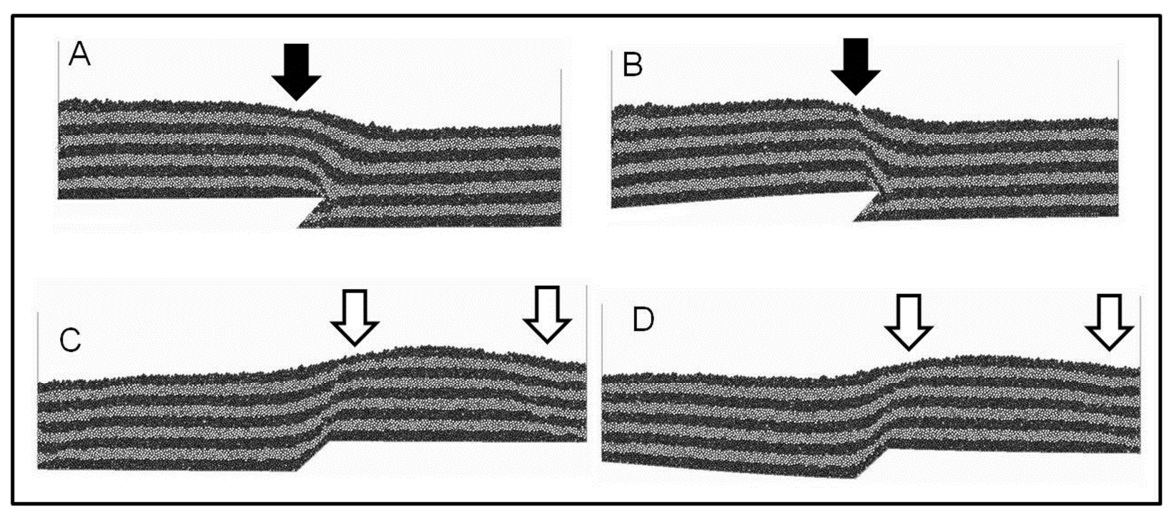

Figure 4. Deformation fields of the sedimentary layer. Black arrows indicate the location of a small hollow at the surface. The area enclosed by white arrows is an upheaval zone. A: Deformation field of a sedimentary layer caused by the motion of a reverse fault at a depth of $15 \mathrm{~km}$. B: Deformation field of sedimentary layer caused by the motion of a reverse fault at a depth of $2.5 \mathrm{~km}$. C: Deformation field of sedimentary layer caused by the motion of a normal fault at a depth of $15 \mathrm{~km}$. D: Deformation field of a sedimentary layer caused by the motion of a normal fault at a depth of $2.5 \mathrm{~km}$.

Although we applied Okada's dislocation solutions as a controller of basement motions in this study, the analytical dislocation solutions based on the viscoelasticity and/or poroelasticity [22, 23, 24, 25] can be also employed. These solutions will contribute to expansion of the application of this modeling procedure. In addition, their use in three-dimensional modeling will play an important role in the study of deformed structures (e.g., flower structure) of sedimentary layers in lateral fault systems

\section{Conclusions}

We attempted to control basement movement by dislocation solutions and to discuss the deformation field of sedimentary layers in connection with fault parameters. As a result, a tilt of all of the sedimentary layers, which did not appear in the rigid basement model, was found, and the basement shape deformed by fault motion controlled deformation of the sedimentary layers. Shapes of the deformed sedimentary layers around the fault tip were different from shapes in the rigid basement model, and the shapes were varied by the fault parameters selected in the modeling, even in the elastic basement model.

Therefore, although the dislocation solutions would only give first-order approximations of the basement deformation fields, especially in case of thick sedimentary layers, the deformed sedimentary layers can be discussed quantitatively in connection with the fault parameters. In addition, because this modeling procedure can calculate the deformed basement shape in arbitrary locations and the superposition principle of solutions is applicable, we can calculate the basement shape, including effects caused by more than one fault motion at arbitrary locations, and we can interpret seismic reflections, geologic structures, and topography by considering regional tectonic background.

\section{Acknowledgment}

This work was supported partially by the Integrated Research Project for Active Fault Systems of the Ministry of Education, Culture, Sports, Science and Technology (MEXT), Japan and the Toyama Prefecture Hitozukuri Foundation. We are most grateful to them. In addition, we are also most grateful to Oya Pamukçu and anonymous reviewer. Our manuscript was improved by their accurate and constructive comments and advices.

\section{References}

[1] P. A., Cundall, "A computer model for simulating progressive large scale movements in blocky rock systems," in Proceedings of the Symposium of the International Society of Rock Mechanics, Nancy, vol. 1, Paper No. II-8, October 1971, pp. 129-136.

[2] P. A., Cundall, and O. D. L., Strack, "A discrete numerical model for granular assemblies," Géotechnique, vol. 29, 1979, pp. 47-65.

[3] M., Cai, P. K., Kaiser, H., Morioka, M., Minami, T., Maejim, Y., Tasak, and H., Kurose, "FLAC/PFC coupled numerical simulation of AE in large-scale underground excavations," Int. J. Rock Mech. Min. Sci., vol. 44, 2007, pp. 550-564. doi:10.1016/j.jirmms.2006.09.013.

[4] J., Hadjigeorgiou, K., Esmaieli, and M., "Grenon, Stability analysis of vertical excavations in hard rock by integrating a fracture system into a PFC model," Tunnel. Undergr. Space Technol., vol. 24, 2009, pp. 296-308. doi:10.1016/j.tust.2008.10.002.

[5] M. A., Antonellini, and D. D., Pollard, "Distinct element modelling of deformation bands in sandstone," J. Struct. Geol., vol. 17, 1995, pp. 1165-1182.

[6] L. M., Strayer, and P. J., Huddleston, "Numerical modelling of fold initiation at thrust ramps," J. Struct. Geol., vol. 19, 1997, pp. 551-566.

[7] J., Imbera, G. W., Tuckwell, C., Childs, J. J., Walsh, T., Manzocchi, A. E., Heath, C. G., Bonson, and J., Strand, "Three-dimensional distinct element modelling of relay growth and breaching along normal faults," J. Struct. Geol., vol. 26, 2004, pp. 1897-1911. doi:10.1016/j.jsg.2004.02.010.

[8] T., Vietor, and O., Oncken, "Controls on the shape and kinematics of the Central Andean plateau flanks: Insights from numerical modeling," Earth Planet. Sci. Let., vol. 236, 2005, pp. 814-827. doi:10.1016/j.epsl.2005.06.004. 
[9] S., Hardy, and E., Finch, "Discrete-element modelling of detachment folding," Basin Res., vol. 17, 2005, pp. 507-520. doi: $10.1111 / \mathrm{j} .1365-2117.2005 .00280 . x$.

[10] S., Hardy, "Structural evolution of calderas: Insights from two-dimensional discrete element simulations," Geology, vol. 36, 2008, pp. 927-930. doi:10.1130/G25133A.1.

[11] D. Y., Wyrick, and K. J., Smart, "Dike-induced deformation and Martian graben systems," J. Volcanol. Geotherm. Res., vol. 185, 2009, pp. 1-11. doi:10.1016/j.jvolgeores.2008.11.022.

[12] S., Hardy, K., McClayc, and J. A., Muñoz, "Deformation and fault activity in space and time in high-resolution numerical models of doubly vergent thrust wedges," Mar. Petrol. Geol., vol. 26, 2009, pp. 232-248. doi:10.1016/j.marpetgeo.2007.12.003.

[13] E. P., Holohan, M. P. J., Schöpfer, J. J., Walsh, "Mechanical and geometric controls on the structural evolution of pit crater and caldera subsidence,” J. Geophys. Res., vol. 116, 2011, B07202. doi:10.1029/2010JB008032.

[14] N., Sakai, S., Kusumoto, and Y., Shimizu, "Numerical simulations of middle-high viscous magma extrusion by means of discrete element modeling," Bull. Volcanol. Soc. Jpn., vol. 58, 2013, pp. 551-555. (in Japanese with English abstract)

[15] Y., Yamada, K., Baba, A., Miyakawa, and T., Matsuoka, "Granular experiments of thrust wedges: Insights relevant to methane hydrate exploration at the Nankai accretionary prism," Mar. Petrol. Geol., vol. 51, 2014, pp. 34-48. doi: 10.1016/j.marpetgeo.2013.11.008.

[16] E., Finch, S., Hardy, and R., Gawthorpe, "Discrete element modelling of contractional fault-propagation folding above rigid basement blocks," J. Struct. Geol., vol. 25, 2003, pp. 515-528.

[17] E., Finch, S., Hardy, and R., Gawthorpe, "Discrete element modelling of extensional fault-propagation folding above rigid basement fault blocks," Basin Res., vol. 16, 2004, pp. 489-506. doi: 10.1111/j.1365-2117.2004.00241.x.

[18] S., Hardy, "Cover deformation above steep, basement normal faults: Insights from 2D discrete element modeling," Mar. Petrol. Geol., vol. 28, 2011, pp. 966-972. doi:10.1016/j.marpetgeo.2010.11.005.

[19] S., Hardy, and E., Finch, "Mechanical stratigraphy and the transition from trishear to kink-band fault-propagation fold forms above blind basement thrust faults: A discrete-element study," Mar. Petrol. Geol., vol. 24, 2007, pp. 75-90. doi:10.1016/j.marpetgeo.2006.09.001.

[20] Y., Okada, "Surface deformation due to shear and tensile faults in a half-space," Bull. Seismol. Soc. Am., vol. 75, 1985, pp. $1135-1154$.

[21] Itasca, 2008, "PFC2D - Particle Flow Code in 2 Dimensions," ver.4.0, Minneapolis, Minnesota.

[22] J. R., Rice, and M. P., Cleary, "Some basic stress diffusion solutions for fluid-saturated elastic porous media with compressible constituents," Rev. Geophys. Space Phys., vol. 14, 1976, pp. 227-241.

[23] Rundle, J. B., 1978, Viscoelastic crustal deformation by finite quasi-static sources: Journal of Geophysical Research, v. 83, p. 5937-5945.

[24] J. B., Rundle, "Viscoelastic-gravitational deformation by a rectangular thrust fault in a layered earth," J. Geophys. Res., vol. 87, 1982, pp. 7787-7796.

[25] M., Matsu'ura, T., Tanimoto, and T., Iwasaki, "Quasi-static displacements due to faulting in a layered half-space with an intervenient viscoelastic layer," J. Phys. Earth, vol. 29, 1981, pp. 23-54. 